COMMENTARY. A review of the World literature concerning febrile convulsions found 37 reports dating from 1929 to 1964, totalling 5,576 patients with febrile convulsions; a mean of $20 \%$ had frequent recurrence of afebrile seizures or epilepsy (range, $2.6 \%-100 \%$ ), and a mean of $27 \%$ had electrographic seizure discharges (range, 3\% - 86\%) [1]. The wide variations in incidence of epilepsy are explained by differences in diagnostic criteria and selection of patients. Those with short febrile seizures were mainly in prospective studies and rarely developed spontaneous seizures, whereas patients with complicated febrile seizures had often presented at a later age with epilepsy, and $17 \%$ had records of brain injury at birth [2]. In a prospective study of 110 unselected FS patients followed for $\sim 2$ years by the author, spontaneous nonfebrile seizures occurred in $17 \%$, they were recurrent in $12 \%$, and were frequent in $4 \%$ [3]. The duration of the FS, a factor not analyzed specifically in the Pavlidou study, and abnormal EEG were most predictive of subsequent epilepsy.

In 1706 children in the US who had experienced at least one FS and were followed to the age of 7 years, epilepsy developed in $2 \%$. In children whose first seizure was complex febrile, epilepsy developed at a rate 18 times higher than in children with no febrile seizures. In patients with simple FS, epilepsy developed in 11 per $1000(1.1 \%)$ [4].

In a UK national population based study of 14,676 children, $398(2.7 \%)$ had at least one FS. The first FS was simple in $80 \%$ and complex in $20 \%$. Epilepsy developed in $9(2.3 \%)$, at a rate similar to that in the US [5]. The early recognition of a heightened susceptibility to epilepsy in a child with FS should lead to the introduction of seizure precautions and EEG surveillance at intervals.

\footnotetext{
References.

1. Millichap JG. Febrile Convulsions. New York: Macmillan; 1968.

2. Lennox MA. J Pediatr. 1949 Oct;35(4):427-35.

3. Millichap JG, et al. Neurology. 1960 Jul;10:643-53.

4. Nelson KB, Ellenberg JH. N Engl J Med. 1976 Nov 4;295(19):1029-33.

5. Verity CM, Golding J. BMJ. 1991 Nov 30;303(6814):1373-6.
}

\title{
EPILEPSY COMORBIDITIES
}

Investigators at Children's Hospital of Pittsburgh, PA; UCLA; and Univ Wisconsin, Madison, WI, draw attention to the lack of attention to comorbidities in the treatment of epilepsy. Comorbidities include depression, anxiety disorders, ADHD, interictal psychosis, autism, and suicidal behavior. Despite studies that demonstrate the frequency of cognitive, psychiatric, linguistic, and social problems, the translation of research data to clinical practice is frequently hindered by limited access to critical cognitive and psychological evaluations and counseling. The NINDS Epilepsy Benchmarks and other national initiatives emphasize the need for comprehensive care for patients with epilepsy, yet there is a continuing lack of interest in support of these goals. (Asato MR, Caplan R, Hermann BP. Epilepsy and comorbidities - What are we waiting for? Epilepsy Behav 2014 Feb;31:127-8).

COMMENTARY. ADHD is a common comorbidity of epilepsy, occurring in one of 5 children with epilepsy [1]. Quality of life was impaired twofold in children with epilepsy complicated by ADHD-inattentive subtype (ADHD-I), and fourfold with 
ADHD-hyperactive-Impulsive subtype (ADHD-C) comorbidity, when compared to nonADHD/epilepsy patients. Methylphenidate with AEDs may be beneficial in treatment of ADHD and AED refractory epilepsy [2][3].

\section{References.}

1. Gross-Tsur V, et al. J Pediatr. 1997 Apr;130(4):670-4.

2. Fosi T, et al. Epilepsia. 2013 Dec;54(12):2071-81.

3. Millichap JG. Pediatr Neurol Briefs. 2014 Feb;28(2):10-11.

\section{TOBACCO SMOKE, NICOTINE AND EPILEPSY}

Investigators at University of South Florida, Tampa, FL, review the literature on the differences between tobacco smoke and nicotine, and their roles in causing or protecting against seizures in animal studies and in humans with epilepsy. In addition to nicotine, tobacco smoke contains many harmful constituents, including carbon monoxide, associated with increasing levels of carboxyhemoglobin $(\mathrm{CO}-\mathrm{Hb})$ in the blood, a potential cause of seizures. The level of $\mathrm{CO}-\mathrm{Hb}$ in non-smokers is $1-2 \%$, in heavy smokers $5-6 \%$, while in patients with seizures it can be as high as $10 \%$. Other chemicals in tobacco smoke that can trigger seizures include ammonia, lead, hexane, toluene, cresol, arsenic, and acetone. Some constituents of tobacco smoke, such as carbon dioxide, have anticonvulsant effects. Even nicotine is reported to control seizures in patients with autosomal dominant nocturnal frontal lobe epilepsy (ADNFLE), the first partial epilepsy syndrome in humans caused by a single gene mutation in the nicotinic acetylcholine receptor (nAChR) gene subunits. For people with a past history of smoking, there is no association between epilepsy risk and the number of cigarettes smoked daily. The etiologies of seizures in chronic smokers are numerous, and include noncompliance with taking AEDs, and multisystem disorders such as COPD. Seizure risks are higher in acute secondhand smokers, chronic active smokers, and babies whose mothers smoke. Tobacco smoking agents can be inactive, proconvulsant, or in some cases, anticonvulsant. (Rong L, Frontera AT Jr, Benbadis SR. Tobacco smoking, epilepsy, and seizures. Epilepsy Behav 2014 Feb;31:210-8).

COMMENTARY. The use of a nicotine patch, gum or inhaler in the treatment of drug refractory ADNFLE is of interest, but the risk of nicotine addiction may be a contraindication. The efficacy and safety of nicotine as an anticonvulsant for severe pharmacoresistant frontal lobe epilepsy requires further study [1][2][3].

\section{References.}

1. Brodtkorb E, Picard F. Epilepsy Behav. 2006 Nov;9(3):515-20.

2. Willoughby JO, et al. Epilepsia. 2003 Sep;44(9):1238-40.

3. Zerem A, et al. Epilepsia. 2013 Jan;54(1):e13-5.

\section{INTRACRANIAL EEG SEIZURE-ONSET PATTERNS}

Investigators at Montreal Neurological Institute and Hospital, Canada, studied intracranial electroencephalographic seizure-onset patterns associated with different epileptogenic lesions, and defined high-frequency oscillation correlates of each pattern. 